\title{
Ruído em centro de esterilização de material cirúrgico de um hospital da região norte do Brasil
}

\author{
Noise in the material and sterilization center of a \\ public hospital in northern Brazil
}

\author{
Francydaiane Silva Gonçalves ${ }^{1}$, Rui Nelson Otoni Magno ${ }^{2}$
}

DOI: http://dx.doi.org/10.11606/issn.2317-2770.v24i1p10-18

\begin{abstract}
Gonçalves FS, Magno RNO. Ruído em centro de esterilização de material cirúrgico de um hospital da região norte do Brasil. Saúde, Ética \& Justiça. 2019;24(1):10-8.

RESUMO: Este estudo teve como objetivo a verificação dos níveis de ruído produzidos no Centro de Material e Esterilização (CME) de um hospital da região norte do Brasil para identificar quais áreas produzem maior quantidade de pressão sonora. O lócus da pesquisa é considerado como um estabelecimento de assistência à saúde de alta complexidade. Como metodologia, lança-se mão de um estudo transversal, descritivo-exploratório, de campo, com abordagem quantitativa. Os dados foram coletados nos meses de junho e julho de 2018, utilizando-se um decibelímetro Icel Manaus DL-4100 para a identificação do nível de pressão sonora (NPS). As medidas foram realizadas no período da manhã e tarde, em horários estabelecidos pelo responsável técnico do setor, baseadas em um momento de maior atividade e outro com baixa atividade nas salas do CME. Como resultado, foram encontrados NPS elevados no local, muito acima do permitido legalmente para jornadas de trabalho. Conclui-se pela necessidade da adoção de medidas que visem à redução dos NPSs na CME e de proteção aos trabalhadores expostos ao ruído nesses ambientes.
\end{abstract}

DESCRITORES: Ruído; Saúde do Trabalhador; Medidores de Ruído.

\footnotetext{
1. Mestranda. Universidade Federal do Pará, Programa de Pós-Graduação em Engenharia de Processos - Mestrado Profissional. E-mail: fdaiane63@hotmail.com.

2. Doutor, docente da Universidade Federal do Pará, Programa de Pós-Graduação em Engenharia de Processos - Mestrado Profissional. E-mail: ruiotoni@ufpa.br.

Endereço para correspondência: Avenida Presidente Vargas, nº 2710, Bairro Aparecida, Santarém, Pará. CEP: 68040060.
} 


\section{INTRODUÇÃO}

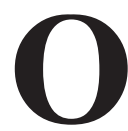

ruído está presente em nosso cotidiano, nas ruas, nas empresas e, também, nos hospitais. Os sons desorganizados, desagradáveis e em frequência fisiologicamente conflitante com a orelha humana são considerados ruídos.

O som é originado por uma vibração mecânica que se propaga pelo ar e chega até o nosso ouvido. Quando essa vibração estimula o aparelho auditivo, ela é chamada de vibração sonora. Assim, o som é definido sendo um conjunto de vibrações ou ondas mecânicas que podem ser ouvidas. O ruído e o barulho são interpretações subjetivas do som. Costuma-se denominar barulho ou ruído todo o som que é indesejável ou fora da faixa permitida, aquele que normalmente costuma causar incômodo ou danos.

Segundo a NR-15 (Norma Regulamentadora -15) ${ }^{1}$, o trabalhador pode permanecer em exposição diária a um nível de ruído de $85 \mathrm{DB}$, com a utilização dos EPIS, em período de até 8 horas diárias de trabalho. Destarte, esta norma acrescenta que as atividades ou operações que exponham os trabalhadores a níveis de ruído, contínuo ou intermitente, superiores a $115 \mathrm{~dB}(\mathrm{~A})$, sem proteção adequada, oferecem risco grave e iminente à saúde do trabalhador, e, ainda, determina que se leve em conta a quantidade de tempo de exposição aos ruídos ${ }^{1}$. A exposição diária a níveis elevados de sons adventícios pode acarretar sérias consequências ao sistema auditivo do profissional e ter consequências para seu bem-estar biopsicossocial, considerando a intensidade dos sons, os níveis pressóricos que o ouvido consegue identificar e suportar, as faixas de frequências audíveis e o limiar de audição. Além da perda auditiva, existem outros impactos e/ou distúrbios atrelados a ruídos intensos e constantes, definidos por Guimarães ${ }^{2}$ como: Alteração do humor, redução da concentração, interferências no metabolismo, risco de distúrbios cardiovasculares, impotência sexual, alterações no sono, irritabilidade, cansaço, diminuição da produtividade, mudanças na respiração do profissional, produção exacerbada de ácido gástrico, cefaleia, alterações musculares, fadiga física e mental, alterações na comunicação, risco acrescido de acidentes de trabalho.

Uma das atividades profissionais relacionadas ao cuidado do paciente é a enfermagem. Segundo a Equipe Biosom $^{3}$, a enfermagem ocupa a $7^{\mathrm{a}}$ posição das 10 profissões consideradas mais barulhentas no mundo. A área da saúde constitui um ramo em que os trabalhadores são bastante expostos a ruídos, devido à produção de sons por equipamentos como os das centrais de esterilização de materiais (CME), os centros cirúrgicos, as unidades de terapia intensiva (UTI), unidades de urgências e emergências e outros setores.

Em hospitais, a Central de Material e Esterilização
(CME) atua como uma zona de apoio técnico aos demais setores e é responsável pelo processamento que compreende: recebimento, seleção, limpeza, desinfecção, preparo dos materiais, esterilização, armazenamento e distribuição dos artigos médico-hospitalares a todas as unidades consumidoras da instituição, proporcionando, assim, condições para a assistência direta e indireta à saúde dos indivíduos considerados enfermos e sadios ${ }^{4}$. As principais fontes emissoras de ruído dentro do CME são: a autoclave em uso, a lavadora ultrassônica de materiais, a conversação da equipe, a movimentação de pessoas, entre outros.

ACME é um setor de grande importância no hospital e a atividade nela desenvolvida, isto é, a esterilização de materiais, envolve diversos processos nos quais atuam profissionais de enfermagem. Durante o processo de limpeza, desinfecção e esterilização utilizam-se muitas máquinas que acabam produzindo diversos ruídos sonoros e que podem ter impacto no profissional atuante na CME. São utilizadas máquinas de lavar por meio da desinfecção térmica e termoquímica, máquinas ultrassônicas, pistolas de secagem, autoclaves e outros aparelhos.

A exposição a níveis elevados de pressão sonora produz incômodo e, se mantida ao longo do tempo, pode ter repercussões para a saúde. Neste estudo foram feitas medições de ruído em uma CME de um hospital público da região Norte do Brasil. As medições foram feitas em horário de atividade da Central com o objetivo de se verificar o nível de ruído a que os profissionais daquele setor se veem expostos durante seu trabalho. O referido hospital tem como missão proporcionar assistência de excelência em saúde de média e alta complexidade aos usuários do Sistema Único de Saúde (SUS), além de proporcionar o ensino e a pesquisa na região.

\section{MÉTODO}

Trata-se de um estudo transversal, descritivo-exploratório, com abordagem quantitativa. A pesquisa do tipo transversal permite a análise de determinados fenômenos de um grupo populacional em um espaço e tempo pré-estabelecido, a pesquisa descritiva-exploratória resulta da análise de dados, através da observação direta e da interação com o objeto a ser estudado. Já a pesquisa com abordagem quantitativa, é caracterizada por meio da tradução dos números e dos elementos que serão classificadas e analisadas por meio de técnicas, e teste estatísticos ${ }^{5}$.

O hospital está situado em uma cidade que tem cerca de 290.000 habitantes como população estimada, é considerada como o centro econômico de sua região e apresenta diversos centros de referência à saúde ${ }^{6}$. Trata-se de um hospital considerado de média e alta complexidade. 
O lócus deste estudo foi a Central de Material de Esterilização, devido a sua diversidade no processo de esterilização e da prestação de serviços a diversas áreas do complexo hospitalar.

\section{Coleta e análise dos dados}

Após a assinatura da carta de anuência da execução da pesquisa pelo gestor do hospital, deu-se início à coleta de dados no setor de recepção e limpeza do CME. O CME possui uma área de $40,34 \mathrm{~m}^{2}$, distribuídos em $12,52 \mathrm{~m}^{2} \mathrm{de}$ área de esterilização, $12,318 \mathrm{~m}^{2}$ de área para preparo do material e 15,505 $\mathrm{m}^{2}$ de área de recepção e limpeza.

Para a obtenção dos valores descritos nas tabelas a seguir foram realizadas medições nos meses de junho e julho de 2018. No mês de junho foram feitas duas coletas por semana. Em julho as coletas eram realizadas todos os dias da semana inclusive no final de semana, posto que nesses dias as atividades no $\mathrm{CME}$ se reduzem ou não ocorrem. As medições em dias de atividades e dias sem atividades são importantes para demonstração das variações de valores em dBs no interior do CME.

Em cada dia da pesquisa foram feitas duas medições, uma no turno da manhã e outra no turno da tarde, cada medição durou 15 (quinze) minutos em cada setor em atividade, esse tempo foi divididos em 5 (cinco) minutos em cada ponto demarcado na sala.

Nas áreas abrangidas pelo CME as características arquitetônicas são: pisos e paredes com azulejos esmaltados e em tamanho padrão, duas janelas de vidro para o recebimento de produtos para saúde utilizados no Centro Cirúrgico (CC) e em outras repartições da instituição, teto com revestimento de concreto.

Objetivando a definição dos possíveis locais e posicionamento do decibelímetro, foi realizado um pré-teste, mensurando-se o nível de pressão sonora (NPS). A mensuração aconteceu durante 5 minutos em cada ponto, no período da manhã e tarde, no início das atividades funcionais, sem interferir nas mesmas.

As medições foram executadas por meio do decibelímetro, Icel Manaus DL-4100®, fabricado seguindo o padrão de normas IEC 61672 tipo 2 e ANSI S1.4 tipo 2, o qual avalia em uma escala de 30 a 130 $\mathrm{dB}$ (dividida em quatro faixas), com precisão de $1,4 \mathrm{~dB}$, circuito de ponderação $\mathrm{A}$ e $\mathrm{C}$, frequências entre $31,5 \mathrm{~Hz}$ e $8 \mathrm{KHz}$ e diferente tempo de resposta (rápida e lenta).

Para realizar a análise dos dados obtidos adotou-se a curva "A" em avaliações em que estejam presentes ruídos contínuos e intermitentes e curva " $\mathrm{C}$ " para ruídos de impacto. Neste estudo, o decibelímetro foi configurado para a resposta lenta, ponderado em $\mathrm{A}$ (dBA). O circuito de resposta lenta é empregado em situações em que o nível de ruído varia excessivamente, obtém-se um valor médio, enquanto o circuito impulsivo é usado para medição de ruídos de impacto. Para a mensuração do
NPS do ambiente objeto de estudo, o decibelímetro foi calibrado, a certificação recebeu o número 06153/17 da ISOMETRO ${ }^{\circledR}$ em 20 de outubro de 2017. Ressalta-se que os NPS obtidos no pré-teste não foram considerados na pesquisa.

As medições foram realizadas nos períodos da manhã, entre $8 \mathrm{~h} 00$ e $12 \mathrm{~h} 00$, e tarde, das $13 \mathrm{~h} 30$ às 17h30, tendo sido estes os horários estabelecidos pelo responsável técnico do CME/SESMET, baseado em um momento de um dia de maior atividade, que acontece no período da tarde, e de outro sem atividade (domingo), no mesmo horário.

As mensurações foram realizadas com 0 decibelímetro posicionado acima de uma mesa de Mayo no centro do local R01, com seu microfone posicionado perpendicularmente a cada parede do ambiente; já para as coletas R02, R03, R04, R05 o aparelho foi fixado a uma altura do solo de 1,50 metros nas paredes dos setores aferidos. Cada direção recebeu um número, para facilitar, visualmente, os resultados nas tabelas.

$\mathrm{O}$ estudo foi efetivado considerando os aspectos éticos e legais da resolução 466/2012 do Conselho Nacional de Saúde (CNS) 7 , não envolvendo diretamente seres humanos, portanto, não foi necessário utilizar o termo de consentimento livre e esclarecido. Porém, foi solicitada a carta de anuência, assinada pelo representante institucional, autorizando, assim, o acesso ao espaço físico e veiculação de fotos.

\section{Sobre o local da coleta de dados: processos operados no CME}

A Anvisa $^{8}$ estabelece que a CME deve ser dividida no mínimo em três áreas: descontaminação, empacotamento, esterilização e estocagem. Assim, o material contaminado é selecionado no expurgo aonde ocorre à limpeza e a descontaminação. Ressalta-se que o recebimento de material contaminado e o expurgo condizem às áreas sujas da CME, e são mais suscetíveis ao processo de infecção. Já o preparo/empacotamento de insumos, a esterilização e o armazenamento dos materiais estão dentro da área denominada limpa, assim os fluxos dos artigos sujos e dos limpos não podem ser cruzados.

O fluxo de uma CME deve ser contínuo e unidirecional dos artigos, evitando o cruzamento de artigos sujos com os limpos e esterilizados, e evitando que o trabalhador escalado para a área contaminada transite pelas áreas limpas e vice-versa. Além disso, o acesso de pessoas deve se restringir aos profissionais da área ${ }^{8}$.

Segundo o Manual de normas e rotinas para o processamento de materiais de enfermagem $/ \mathrm{médico/}$ odontológico ${ }^{9}$, no $\mathrm{CME}$, o processamento dos artigos tem início na área suja (que consiste na separação dos materiais e na realização do processo de limpeza, descontaminação, desinfecção, esterilização e secagem 
dos instrumentais), passa para área limpa (onde ocorre a separação dos instrumentais, conferência da limpeza, funcionalidade e integridade dos artigos, bem como o empacotamento e a selagem dos materiais) e, por fim, na área de guarda (local destinado à estocagem dos instrumentais esterilizados e a dispensação dos mesmos).

Neste contexto, os principais passos para a limpeza de materiais são a desinfecção e esterilização dos insumos utilizados nas unidades hospitalares. Esta fase é definida como a remoção de sujidades realizada pela aplicação de energia mecânica (fricção), química (soluções detergentes, desincrostantes ou enzimática) ou térmica ${ }^{10}$.

A descontaminação está atrelada a minimização das bactérias e/ou dos microrganismos em geral dos artigos, com a finalidade de conceber ao profissional da CME um manuseio com maior segurança. Já o processo de desinfecção é caracterizado como a destruição dos microrganismos através do uso de agentes físicos ou químicos, titulados como desinfectantes ou germicidas apropriados para destruir os agentes infecciosos em um espaço de tempo operacional de 10 a $30 \mathrm{~min}^{10}$.
A esterilização, por sua vez, consiste na etapa final do processamento de artigos e é conceituada como a remoção e/ou a destruição total dos microrganismos ainda operantes nos materiais. Assim, mediante a tal definição, sabe-se que a esterilização na área da saúde ocorre no diaa-dia através do uso do calor (na forma úmida ou seca), dos meios químicos (liquida, gasosa e plasma). Ademais, nas CMEs a forma mais utilizada é a autoclavação por vapor saturado de pressão, método responsável pela maior geração de ruído do setor.

\section{RESULTADOS E DISCUSSÃO}

Constatou-se que a área de secagem apresentou maior nível de ruído, com 109,64 dB, seguida do expurgo, com $92,59 \mathrm{~dB}$ e de $91,98 \mathrm{~dB}$ para a sala de preparo de material. Estas três medidas estão acima dos $87 \mathrm{~dB}$ permitidos pela legislação brasileira para uma jornada de trabalho de 6 horas diárias ${ }^{1}$. Apenas a "arsenal", com valores de 85,03dB em média, está de acordo com os parâmetros de exposição preconizados legalmente:

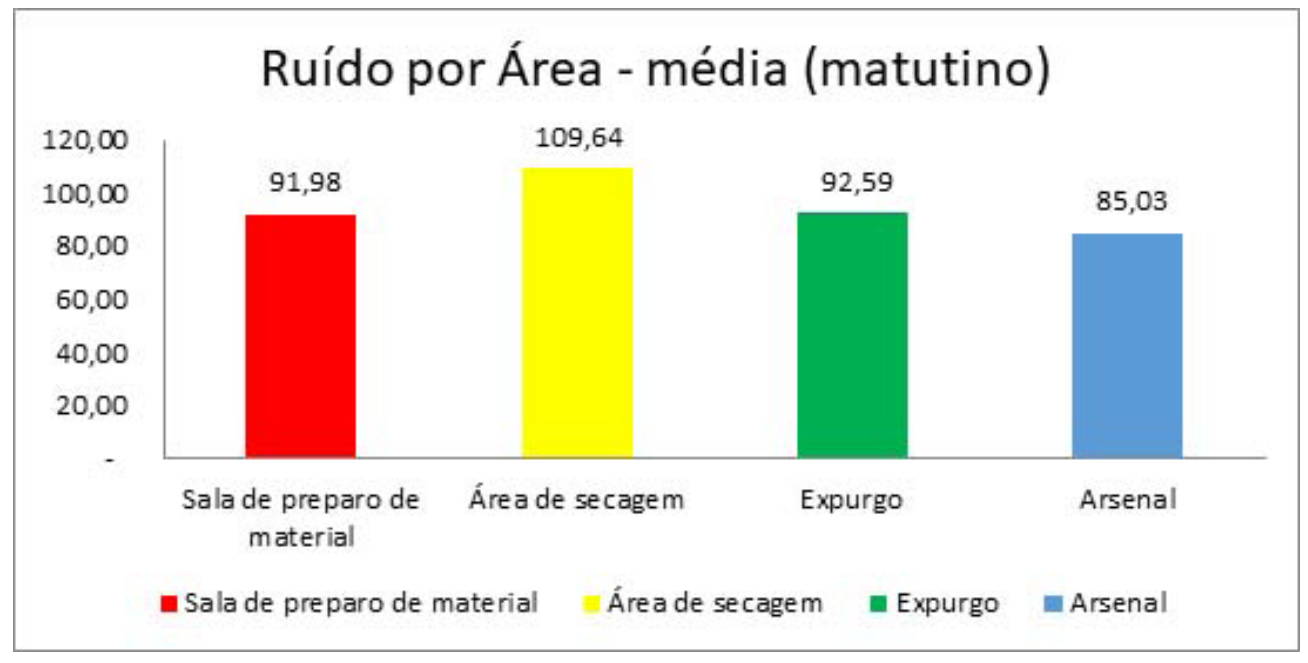

Figura 1 - Gráfico do nível de ruído médio por área - turno matutino

A Tabela 1 apresenta os resultados da análise estatística considerando o total de 225 medidas durante o turno vespertino, no qual se obteve a média geral, valor máximo e mínimo, amplitude total, número de classes, amplitude das classes, desvio padrão amostral e amplitude das classes (incremento) para cálculo e construção do histograma e da distribuição de frequência.

Observa-se pela Tabela 1 que a média geral dos valores mensurados apresenta resultado de 94,24 dB, valor acima do que é permitido pela legislação, que é de $87 \mathrm{~dB}$ para um regime de trabalho de 6 horas diária ${ }^{1}$. Esta média alta se deve à quantidade de medições com valores acima de $110 \mathrm{~dB}$, correspondente a 36, como se vê na Tabela 2.
Tabela 1- Tabela de dados da amostra considerando a média geral no turno matutino

\begin{tabular}{|c|c|}
\hline Descrição & Valor \\
\hline Tamanho da Amostra & 225 \\
\hline Média Geral & 94,24 \\
\hline Máximo Valor & 131,1 \\
\hline Mínimo Valor & 74,9 \\
\hline Amplitude Total & 56,2 \\
\hline Número de Classes & 15,00 \\
\hline Amplitude das Classes & 3,75 \\
\hline Desvio Padrão Amostral & 9,92 \\
\hline Amplitude das Classes DF & 0,249778 \\
\hline
\end{tabular}


Tabela 2 - Tabela de dados para histograma considerando a média geral no turno matutino

\begin{tabular}{c:c:c}
\hline Número de Classes & Corte & Frequência \\
\hline 1 & 79 & 8 \\
\hline 2 & 82 & 23 \\
3 & 86 & 13 \\
\hline 4 & 90 & 4 \\
\hline 5 & 94 & 102 \\
\hline 6 & 97 & 25 \\
\hline 7 & 101 & 4 \\
\hline 8 & 105 & 8 \\
\hline 9 & 109 & 2 \\
\hline 10 & 112 & 27 \\
11 & 116 & 8 \\
12 & 120 & 0 \\
13 & 124 & 0 \\
\hline 14 & 127 & 0 \\
\hline 15 & 131 & 1 \\
\hline \hline
\end{tabular}

A Tabela 2 apresenta a distribuição dos valores dentro das 15 classes, sendo considerado o intervalo fechado no limite inferior e intervalo aberto no limite superior para cada classe. Observa-se no número de classe 5, intervalo de 90 (fechado) e 94 (aberto), uma maior concentração de valores medidos sendo um total de 102 medições.

A Figura 2 apresenta os valores distribuídos em torno da média. São observadas 35 medições acima de $110 \mathrm{~dB}$, mas quando comparado o valor permitido pela legislação, $87 \mathrm{~dB}$ para 6 horas diárias ${ }^{1}$, temos 177 medições, o que corresponde a aproximadamente $79 \%$ do total das medidas.

A média do turno vespertino será averiguada a partir da próxima Figura 5.

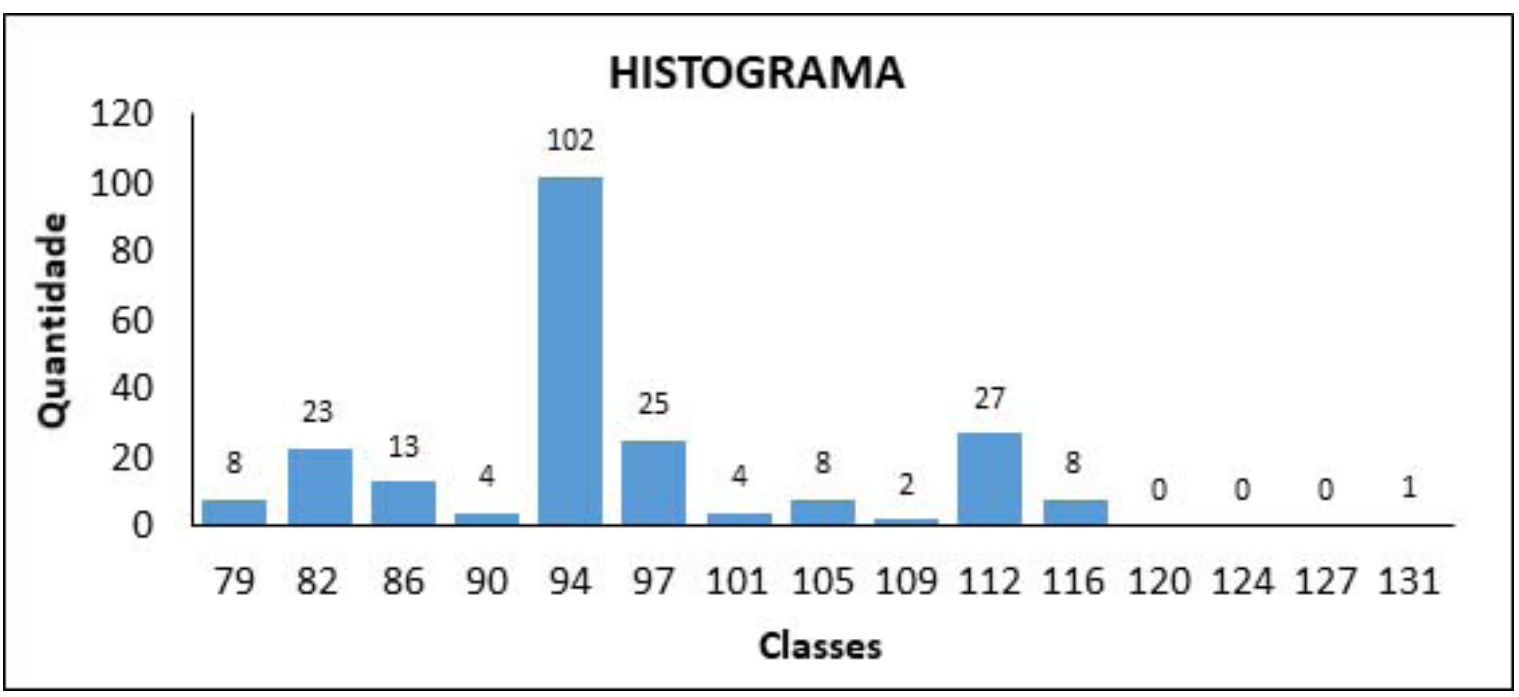

Figura 2 - Histograma considerando a média geral no turno matutino

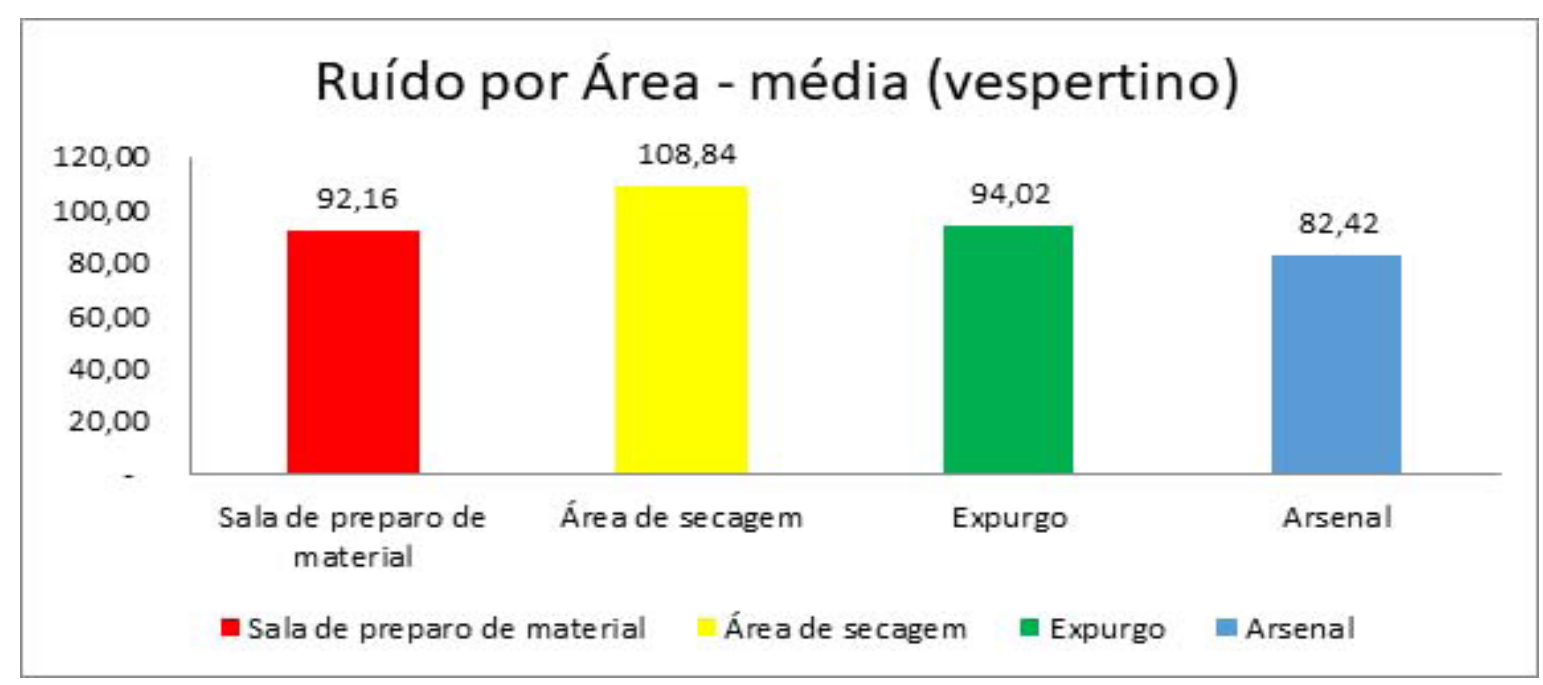

Figura 3 - Gráfico do nível de ruído médio por área - turno vespertino 
A Figura 3 apresenta a média das aferições do turno vespertino. A produção de ruídos nas salas manteve-se na média. Na sala do arsenal, no entanto, a diminuição da produção de ruídos se manteve caindo de 85,90 para $80,30 \mathrm{~dB}$. Essa diminuição se dá por conta do não funcionamento das máquinas desse setor no período da tarde e não havia nenhum servidor na sala. $\mathrm{O}$ ruído aferido corresponde ao produzido pela máquina de autoclave que se mantém na sala ao lado.

Tabela 3 - Apresenta os dados da amostra considerando a média geral no turno matutino para análise estatística

\begin{tabular}{|c|c|}
\hline Descrição & Valor \\
\hline Tamanho da Amostra & 225 \\
\hline Média Geral & 93,92 \\
\hline Máximo Valor & 113,7 \\
\hline Mínimo Valor & 73,2 \\
\hline Amplitude Total & 40,5 \\
\hline Número de Classes & 15 \\
\hline Amplitude das Classes & 2,70 \\
\hline Desvio Padrão Amostral & 9,96 \\
\hline Amplitude das Classes DF & 0,18 \\
\hline
\end{tabular}

A Tabela 3 apresenta resultados da análise estatística considerando o total de 225 medidas durante o turno matutino, na qual se obteve a média geral, valor máximo e mínimo, amplitude total, número de classes, amplitude das classes, desvio padrão amostral e amplitude das classes (incremento) para cálculo e construção do histograma e da distribuição de frequência. A média geral dos valores medidos apresenta resultado de 93,92 dB, o qual se encontra acima do valor de tolerância permitido pela legislação que é de $87 \mathrm{~dB}$, para um regime de trabalho de 6 horas diária ${ }^{1}$.

Tabela 4 - Tabela dados para histograma considerando a média geral no turno matutino

\begin{tabular}{|c|c|c|}
\hline Número de Classes & Corte & Frequência \\
\hline 1 & 76 & 2 \\
\hline 2 & 79 & 10 \\
\hline 3 & 81 & 16 \\
\hline 4 & 84 & 17 \\
\hline 5 & 87 & 5 \\
\hline 6 & 89 & 1 \\
\hline 7 & 92 & 36 \\
\hline 8 & 95 & 72 \\
\hline 9 & 98 & 12 \\
\hline 10 & 100 & 2 \\
\hline 11 & 103 & 9 \\
\hline 12 & 106 & 5 \\
\hline 13 & 108 & 0 \\
\hline 14 & 111 & 12 \\
\hline 15 & 114 & 25 \\
\hline
\end{tabular}

A Tabela 4 apresenta o tratamento de dados para as 225 medições e sua distribuição nos intervalos de cada classe, ou seja, na classe 1 o valor mínimo é 73,2 (tabela 4.2) e valor máximo permitido dentro desta classe deve ser menor que 76, representando o corte, para a segunda classe serão considerados valores maiores e/ou iguais a 76 e menos que 79, e assim sucessivamente. Esta tabela serve para construção do gráfico de histograma, o qual permite observar o comportamento dos dados entorno de valor central (média geral).

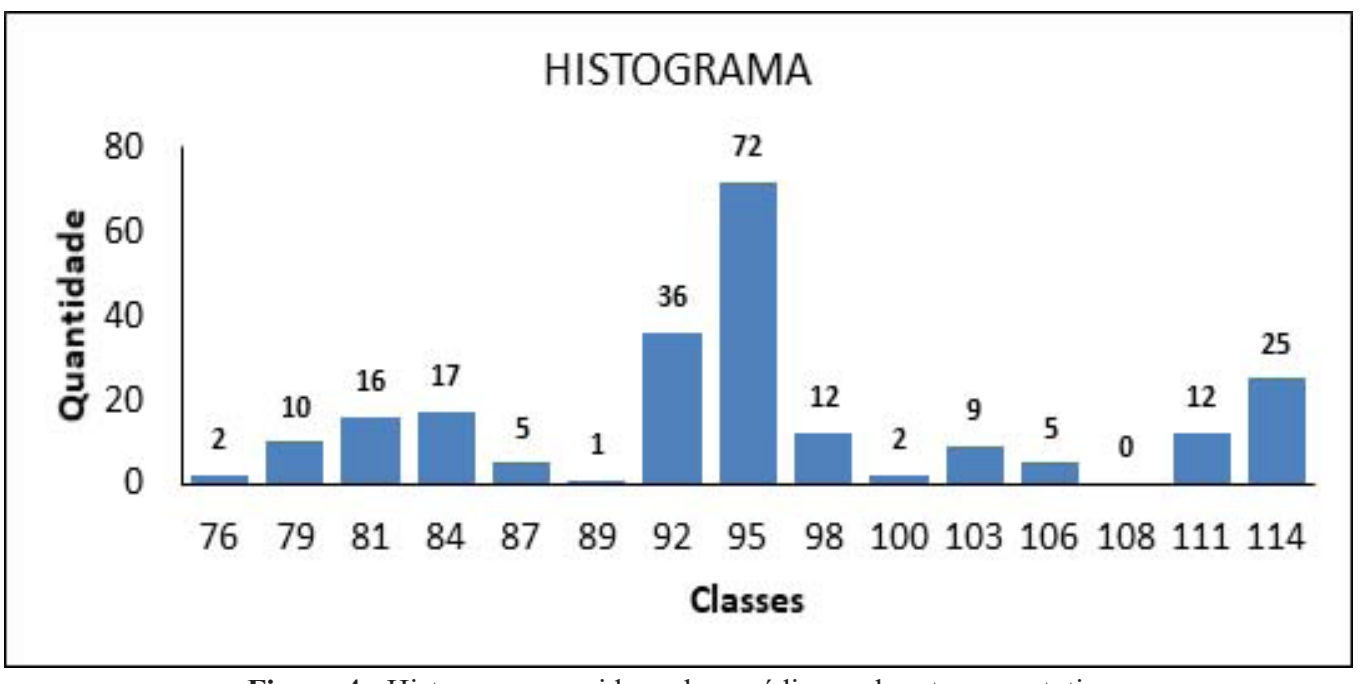

Figura 4 - Histograma considerando a média geral no turno matutino 
A Figura 4 apresenta os gráficos de histograma e da distribuição de frequência, respectivamente. Ambos consideram o valor central a média geral amostral. A vantagem de ambos os gráficos é uma melhor visualização da distribuição das medidas. Observa-se que a média amostral é fortemente influenciada pelas 37 medidas que apresentaram valores acima de $110 \mathrm{~dB}$.

\section{Condições de salubridade e as principais fontes emissoras de ruídos no $\mathrm{CME}$}

As principais fontes emissoras de ruído dentro da CME são a autoclave em uso, a lavadora ultrassônica de materiais, a conversação da equipe e a movimentação de pessoas.

Os colaboradores do CME estudado trabalham por escala quinzenal na qual todos os funcionários ficam escalados 15 dias em cada setor. $\mathrm{O}$ funcionamento da central é de segunda a domingo e feriados nos turnos manhã, tarde e noite, conforme escala. Alguns funcionários trabalham numa escala de 12 horas, de segunda a sexta e os demais numa escala de 6 horas.

Analisando os dados resultantes das aferições no CME e comparando com o tempo máximo de exposição permitido pela NR 15 para a carga horária de trabalho de 6 horas $(87 \mathrm{~dB})^{1}$, chegamos a um resultado bastante esclarecedor sobre as condições de trabalho, no que se refere à exposição ao ruído, dos profissionais desse setor, visto que apenas a sala do arsenal é mantida em um nível permitido pelas normas, e esse nível se mantém somente no período vespertino, pois no matutino a produção de ruídos varia de 88,27 a $89,97 \mathrm{~dB}$, portanto, acima do permitido legalmente.

Nas salas de preparo, secagem e expurgo, esses valores são consideravelmente mais altos, variando de 90,70 a 93,$38 ; 108,33$ a 112,40 e 88,77 a 103, 20, respectivamente. Para se chegar a esse número buscaramse os valores mais baixos e os mais altos produzidos nos turnos matutino e o vespertino.

Se levarmos em consideração que os profissionais do hospital trabalham geralmente por 6 horas diárias, e são escalados para passar por cada uma das salas do CME, se consideramos também que esses valores estão acima da média estabelecida pelo anexo I da NR 15 que estabelece $87 \mathrm{~dB}$ de ruídos para exposição diária máxima de 6 horas, chega-se à conclusão de que o CME é um lugar insalubre para a presença humana ${ }^{1}$.

Vale destacar que na sala de secagem esses valores são os mais altos e potencialmente prejudiciais à saúde do trabalhador, chegando a variar entre 108, 33 a $112,40 \mathrm{~dB}$, o que representa uma produção média de ruídos de 110, $36 \mathrm{~dB}$. Para uma escala de $110 \mathrm{~dB}$ a NR 15 estabelece que a exposição diária máxima permitida é de 15 minutos $^{1}$. Entretanto, ainda com esses altos níveis de produção de ruídos, os profissionais do CME do hospital possuem, geralmente, uma carga horária de trabalho de 6 horas por dia, e existem aqueles que fazem plantão de 12 horas, o que eleva ainda mais os riscos ocupacionais.

Durante as coletas observou-se que os funcionários não têm hábito de usar os equipamentos de proteção individual (EPI's), principalmente na sala de preparo, onde ficam ligadas as autoclaves. Nessa sala em especial o ruído é intenso, tanto pelas máquinas quanto pelas conversas entre funcionários. Observou-se, também, que a maioria dos colaboradores fala muito alto, na tentativa de que sua voz se sobressaia aos ruídos produzidos na sala.

Verificou-se que mesmo fora do ambiente de trabalho os colaboradores mantêm a tendência de falar com a voz alta, o que pode indicar problemas de saúde auditiva. Verificou-se o uso adequado de EPI's apenas no setor de expurgo e na área de secagem.

Sabemos que a Associação Brasileira de Normas Técnicas (ABNT) recomenda de 35 a $45 \mathrm{~dB}(\mathrm{~A})$ como níveis aceitáveis para diferentes ambientes hospitalares e $87 \mathrm{~dB}$ para ambientes fechados produtores de ruídos ${ }^{11}$. Estes limites são frequentemente ultrapassados nesta CME, o que pode ter efeitos nocivos, principalmente problemas auditivos, para os trabalhadores do setor.

Segundo Oliveira e Arenas ${ }^{12}$, a exposição ocupacional a altos níveis de ruídos por um período prolongado está associada a várias manifestações sistêmicas, tais como: elevação no nível geral de vigilância, fadiga, aceleração da frequência cardíaca e respiratória, alteração da pressão arterial e da função intestinal, dilatação das pupilas, aumento do tônus muscular, aumento da produção de hormônios tireoidianos, estresse, enxaqueca, dores corporais, entre outros.

Otenio et al. ${ }^{13}$, por sua vez, defendem que com o ambiente livre de ruídos, ou com NPS adequados para cada tipo de ambiente, os profissionais ficam psicologicamente menos cansados e estressados, possibilitando que eles tenham motivação para trabalhar e um maior rendimento profissional.

\section{CONCLUSÃO}

Este estudo constatou a existência de elevados níveis de pressão sonora nas instalações do CME do hospital pesquisado. Nos períodos avaliados, o valor médio encontrado foi de $96,35 \mathrm{~dB}$, com variação entre 80,30 e 112,40 dB em dias de atividade. Estes valores estão acima do preconizado para ambientes hospitalares fechados e, caso sejam mantidos durante a jornada de trabalho, a exposição cotidiana a eles tende a ser nociva à saúde dos profissionais da CME.

As salas de preparo, secagem e expurgo são as que geram níveis mais elevados de pressão sonora no CME. A sala do arsenal é a que menos gera ruídos, até 
mesmo pela natureza do ambiente. Os ruídos captados nessa sala são decorrentes, em grande parte, da máquina de autoclave que fica na sala da esterilização.

Apesar da disponibilidade de EPIs nos setores do CME, observou-se pouca adesão ao uso desses equipamentos pelos colaboradores. Seria importante compreender a razão da baixa adesão, uma vez que os EPIs poderiam atenuar os efeitos nocivos do ruído ambiental e suas eventuais repercussões.

Embora o ideal fosse a utilização de um dosímetro para medir a exposição ao ruído durante toda a jornada dos trabalhadores, os resultados obtidos apontam para níveis sonoros considerados elevados, a cuja exposição podem estar atrelados eventuais efeitos nocivos, dependendo do tempo de exposição. Isso aponta para a necessidade de estudos mais detalhados e para a importância da adoção de medidas que visem à diminuição dos níveis de pressão sonora bem como de proteção dos trabalhadores a esta exposição.

O monitoramento de cada fase do processamento de produtos e equipamentos hospitalares, assim como a descrição de todos os procedimentos operacionais de forma padronizada é fundamental. Para tanto, estudos com a finalidade de aperfeiçoar o processo de trabalho no CME são necessários. E, nesse contexto, a preocupação com o bem-estar e a saúde dos trabalhadores também deve ser considerada, lembrando que a exposição cotidiana a elevados níveis de pressão sonora é bastante nociva.

Gonçalves FS, Magno RNO. Noise in the Material and Sterilization Center of a public hospital in northern Brazil. Saúde, Ética \& Justiça. 2019;24(1):10-8.

\begin{abstract}
This study aimed to verify noise levels at the Material and Sterilization Center (CME) of a hospital in northern Brazil, to identify which areas produce a greater amount of sound pressure. The researched establishment is considered a high complexity healthcare unit. A cross-sectional, descriptive exploratory field study was conducted, with a quantitative approach. The data were collected in June and July 2018, using an Icel Manaus DL 4100® decibel meter to identify sound pressure levels (NPS). The measurements were taken in the morning and afternoon. The specific times were established by the sector's responsible technician. The choice was based on the moments with the highest and lowest levels of activity in the rooms of the CME. As a result, high NPS were found at the site.
\end{abstract}

KEY WORDS: Noise; Occupational Health; Noise Meters.

\section{REFERENCIAS}

1. Brasil. Ministério do Trabalho. Norma Regulamentadora $\mathrm{N}^{\circ}$ 15: Atividades e operações insalubres [Internet]. [Acesso em 2018 mai. 20]. Disponível em: https://enit.trabalho.gov. br/portal/images/Arquivos SST/SST NR/NR-15.pdf

2. Guimarães JR. Impacto dos ruídos em máquinas injetoras e métodos de controle [Dissertação] [Internet]. Belém: Universidade Federal do Pará; 2016. [Acesso em 2018 mai. 15]. Disponível em: http://ppgep.propesp.ufpa.br/ ARQUIVOS/dissertacoes/Dissertacao2016-PPGEP-MPJosinetedaRochaGuimaraes

3. Equipe Biosom. Perda Auditiva Induzida por Ruído (PAIR): Classificação, Causas e Ocupacional [Internet]. Brasil; 2014. [Acesso em 2018 mai. 20]. Disponível em: https:// biosom.com.br/blog/saude/pair-perda-auditiva-induzidapor-ruido/

4. Ramos EMNM, Costa MFR, Oliveira OC, Ikeda T, Guimarães ZS (elaboradores). Central de Material e Esterilização: Manual Técnico. Brasília; 2002.

5. Marconi MA, Lakatos EM. Metodologia do trabalho científico: procedimentos básicos, pesquisa bibliográfica, projeto e relatório, publicações e trabalhos científicos. $7^{\mathrm{a}}$ ed. São Paulo: Atlas; 2011.

6. Instituto Brasileiro de Geografia e Estatística. Cidades do
Pará - Santarém [Internet]. Rio de Janeiro; 2019. [Acesso em 2019 fev. 22]. Disponível em: https://www.ibge.gov.br/ cidades-e-estados/pa/santarem.html?

7. Associação Brasileira de Normas Técnicas. NBR-10151: Acústica - Avaliação do ruído em áreas habitadas, visando o conforto da comunidade - Procedimento. Rio de Janeiro; 2000.

8. Brasil. Ministério da Saúde. Agência Nacional de Vigilância Sanitária. Resolução RDC n 307, de 14 de novembro de 2002. Altera a Resolução - RDC $n^{\circ} 50$ de 21 de fevereiro de 2002 que dispõe sobre o Regulamento Técnico para planejamento, programação, elaboração e avaliação de projetos físicos de estabelecimentos assistenciais de saúde [Internet]. Brasília, DF; 2002. [Acesso em 2018 mai. 20]. Disponível em: http:/www.saude.mg.gov.br/images/ documentos/RES_307.pdf

9. São Paulo. Prefeitura Municipal de Campinas. Secretaria Municipal de Saúde. Manual de normas e rotinas para o processamento de materiais de enfermagem $/$ médico/ odontológico. Campinas; 2014.

10. Souza PC. Análise das condições de trabalho na central de materiais esterilizados do hospital municipal de barra do Bugres - MT. In: XXX Encontro Nacional de Engenharia de Produção; 2010; São Carlos. São Carlos: Associação Brasileira de Engenharia de Produção; 2010. 
Gonçalves FS, Magno RNO. Ruído em centro de esterilização de material cirúrgico de um hospital.

11. Associação Brasileira de Normas Técnicas. NBR 10152: Acústica - Níveis de pressão sonora em ambientes internos a edificações. Rio de Janeiro; 2017.

12. Oliveira CRD, Arenas GWN. Exposição ocupacional a poluição sonora em anestesiologia. Rev Bras Anestesiol.

dx.doi.org/10.1590/S0034-72992007000200016

Recebido em: 10/03/2019

Aprovado em: 29/06/2019
2012;62(2):257-61. DOI: http://dx.doi.org/10.1590/S003470942012000200011

13. Otenio MH, Cremer E, Claro EMT. Intensidade de ruído em hospital de 222 leitos na $18^{\mathrm{a}}$ Regional de Saúde - PR. Rev Bras Otorrinolaringol. 2007;73(2):245-50. DOI: http:// 